\title{
Response of depression to botulinum toxin treatment: agitation as a predictor
}

\author{
Roumen Milev * \\ Department of Psychiatry, Queen's University, Kingston, ON, Canada
}

Keywords: major depressive disorder, botulinum toxin, prediction, treatment, agitation

\section{A commentary on}

Agitation predicts response of depression to botulinum toxin treatment in a randomized controlled trial

by Wollmer MA, Kalak N, Jung S, de Boer C, Magid M, Ruichenberg JS, et al. Front Psychiatry (2014) 5:36. doi: 10.3389/fpsyt.2014.00036

Major depressive disorder (MDD) is a mental disorder, characterized by low mood, lack of interest or pleasure, and a cluster of other vegetative and cognitive symptoms, occurring for a period of time and causing significant distress or impairment of functioning. It has a relapsing and recurring course, sometimes becomes chronic. It is a common disorder with a life time prevalence of $16.6 \%$ (1) and 12 months prevalence of $6.7 \%$ (2). MDD affects patients' functioning and is associated with significant personal and societal burden.

It was predicted that MDD would rank second by disability adjusted life years (DALY) among all disorders worldwide in year 2020, contributing with 5.7\% of DALY and second only to ischemic heart disease (3).

The episodes of depression in MDD, if left untreated, may last for months or years. There are many treatments available for depression including psychotherapy (4), pharmacotherapy (5), neurostimulation (6), and other complementary and alternative medicine methods (7), as summarized in the CANMAT clinical practice guidelines. Although there are numerous treatments available, the results are far from ideal, with significant proportion of patients not achieving remission and continuing to suffer with symptoms of the disorder and functional impairment. Therefore, the quest for new and better treatment approaches is continuing.

There is a small but growing body of evidence suggesting that botulinum toxin may be useful for treatment of depression. Botulinum toxin is a protein produced by Clostridium Botulinum and is highly toxic and lethal. In medical use, when injected, it induces strong flaccid muscle paralysis, and this effect is used in the treatment of a variety of different disorders characterized by muscle over activity and spasticity and in hyperhidrosis. More recently, botulinum toxin use has skyrocketed in cosmetic medicine, where it leads to significant visual improvement of wrinkles, due to the paralysis of the underlying muscles.

The main hypothesis for the proposed beneficial effects of botulinum toxin in depression is through the facial feedback. Low mood and depression are often associated with sad facial expression. It has long been observed that MDD patients often have deep vertical frown lines and different signs, such as "omega melancholicum" sign and Veraguth's folds, have been described (8). Injecting botulinum toxin and improving facial expression would lead to improvement of symptoms of depression.

In an open study of botulinum toxin injected into the frown muscles of 10 depressed patients, Finzi and Wasserman (9) reported that 8 of the 10 patients went into 
remission after one treatment of botulinum toxin. This observation was followed by a small randomized, double blind, controlled trial by Wollmer et al. (10), who examined 30 patients randomly assigned to receive injection of botulinum toxin or saline placebo. The patients were mainly women and the authors reported response rate [as measured by $50 \%$ improvement on Hamilton Depression Rating Scale (HAM-D)] of $60 \%$ in the active group vs $13.3 \%$ in the placebo group. Of interest, the presence of significant vertical frown line was required in order to be included in this study. Soon after, a larger randomized controlled trial was reported by Finzi and Rosenthal (11), which included 85 patients. This study used Montgomery-Asberg Depression Rating Scale (MADRS) as the primary outcome measure and did not require a pronounced vertical frown for inclusion in the study, but the results were very similar to the study by Wollmer. One issue discussed in both randomized and controlled trials was the fact that most patients guessed correctly whether they were in the placebo group or in the botulinum

\section{References}

1. Kessler RC, Berglund P, Demler O, Jin R, Merikangas KR, Walters EE. Lifetime prevalence and age-of-onset distributions of DSM-IV disorders in the National Comorbidity Survey Replication. Arch Gen Psychiatry (2005) 62(6):593-602. doi:10.1001/archpsyc.62.6.617

2. Kessler RC, Chiu WT, Demler O, Walters EE. Prevalence, severity, and comorbidity of 12-month DSM-IV disorders in the National Comorbidity Survey Replication. Arch Gen Psychiatry (2005) 62(6):617-27. doi:10.1001/archpsyc. 62.6.617

3. Murray CJ, Lopez AD. Alternative projections of mortality and disability by cause 1990-2020: Global Burden of Disease Study. Lancet (1997) 349(9064):1498-504. doi:10.1016/S0140-6736(96)07495-8

4. Parikh SV, Segal ZV, Grigoriadis S, Ravindran AV, Kennedy SH, Lam RW, et al. Canadian Network for Mood and Anxiety Treatments (CANMAT) clinical guidelines for the management of major depressive disorder in adults. II. Psychotherapy alone or in combination with antidepressant medication. J Affect Disord (2009) 117:S15-25. doi:10.1016/j.jad.2009.06.042

5. Lam RW, Kennedy SH, Grigoriadis S, McIntyre RS, Milev R, Ramasubbu $\mathrm{R}$, et al. Canadian Network for Mood and Anxiety Treatments (CANMAT) clinical guidelines for the management of major depressive disorder in adults. III. Pharmacotherapy. J Affect Disord (2009) 117:S26-43. doi:10.1016/j.jad. 2009.06.041

6. Kennedy SH, Milev R, Giacobbe P, Ramasubbu R, Lam RW, Parikh SV, et al. Canadian Network for Mood and Anxiety Treatments (CANMAT) clinical guidelines for the management of major depressive disorder in adults. IV. Neurostimulation therapies. J Affect Disord (2009) 117:S44-53. doi:10.1016/j. jad.2009.06.039

7. Ravindran AV, Lam RW, Filteau MJ, Lespérance F, Kennedy SH, Parikh SV, et al. Canadian Network for Mood and Anxiety Treatments (CANMAT) clinical toxin active group, which might have also influenced their response rates.

In the current post hoc analysis (12) of their original study (10), Wollmer et al. are trying to determine predictors for better response to botulinum toxin in patients with MDD. After conducting further analysis of the data, they found that high baseline agitation (as measured on item 9 of HAM-D) is the main predictor of response to botulinum toxin with sensitivity of $100 \%$, specificity of $56 \%$, and overall precision of $87 \%$. Agitation may be associated with more dynamic motor activity, leading to more changes in the facial expression. The baseline appearance of the glabellar frown line was not a predictor in this analysis.

All the limitations of this study (e.g., small size, post hoc analysis, etc.) are known and clearly stated. Nevertheless, this type of analysis brings an important clinical point: we not only need to know which treatment works, but also who are the patients that would likely benefit most! The authors are to be commended on this fine attempt to answer that.

guidelines for the management of major depressive disorder in adults. V. Complementary and alternative medicine treatments. J Affect Disord (2009) 117:S54-64. doi:10.1016/j.jad.2009.06.040

8. Greden JF, Genero N, Price HL. Agitation-increased electromyogram activity in the corrugator muscle region: a possible explanation of the "Omega sign"? Am J Psychiatry (1985) 142(3):348-51. doi:10.1176/ajp.142.3.348

9. Finzi E, Wasserman E. Treatment of depression with botulinum toxin A: a case series. Dermatol Surg (2006) 32(5):645-50. doi:10.1111/j.1524-4725.2006. 32136.x

10. Wollmer MA, de Boer C, Kalak N, Beck J, Götz T, Schmidt T, et al. Facing depression with botulinum toxin: a randomized controlled trial. J Psychiatr Res (2012) 46(5):574-81. doi:10.1016/j.jpsychires.2012.01.027

11. Finzi E, Rosenthal NE. Treatment of depression with onabotulinumtoxinA: a randomized, double-blind, placebo controlled trial. J Psychiatr Res (2014) 52:1-6. doi:10.1016/j.jpsychires.2013.11.006

12. Wollmer MA, Kalak N, Jung S, de Boer C, Magid M, Reichenberg JS, et al. Agitation predicts response of depression to botulinum toxin treatment in a randomized controlled trial. Front Psychiatry (2014) 5:36. doi:10.3389/fpsyt. 2014.00036

Conflict of Interest Statement: The author declares that the research was conducted in the absence of any commercial or financial relationships that could be construed as a potential conflict of interest.

Copyright (C) 2015 Milev. This is an open-access article distributed under the terms of the Creative Commons Attribution License (CC BY). The use, distribution or reproduction in other forums is permitted, provided the original author(s) or licensor are credited and that the original publication in this journal is cited, in accordance with accepted academic practice. No use, distribution or reproduction is permitted which does not comply with these terms. 